\title{
A reply to "Sonographic assessment of the retroperitoneal position of the third portion of the duodenum: an indicator of normal intestinal rotation"
}

\author{
David K. Yousefzadeh
}

Received: 20 August 2012 / Accepted: 23 August 2012 /Published online: 5 October 2012

(C) Springer-Verlag 2012

Sir,

With interest I noticed your recent online publication of "Sonographic assessment of the retroperitoneal position of the third portion of the duodenum: an indicator of normal intestinal rotation" [1].

I wish to congratulate you in furthering the use of US as the first imaging test to diagnose or exclude malrotation and on validating our previous works [2-4]. Furthermore, your contribution decisively alleviated the concerns and responded to the reservations that were expressed in an editorial regarding our original contribution [5] and proved them to be unwarranted.

In this friendly communication, I wish to express my concerns about how my views have been misrepresented in your article and reiterate my reservations regarding Dr. Taylor's paper [6] because they have not been accurately reflected by you as they were originally enumerated in the letter to the editor [7].

In your paper you stated the following:

"Recently, Taylor [6] reviewed abdominal CTs in 100 normal subjects and in 38 children with surgically proven malrotation and demonstrated the position of the D3 between the SMA and the aorta in all studies of normally rotated gut without any false-positive findings. In his group of 38 children with surgically proven malrotation, only one had a normally positioned D3. We fully agree with Yousefzadeh's [7] expressed reservations regarding the use of CT."

My reservations [7] did not question the wisdom of using $\mathrm{CT}$ or its value in diagnosing or excluding malrotation as your statement indicates. For sure, the language suggests

D. K. Yousefzadeh $(\bowtie)$

Department of Radiology, The University of Chicago,

5841 S. Maryland Ave., MC 2026,

Chicago, IL 60637, USA

e-mail: dyousefz@radiology.bsd.uchicago.edu

e-mail: dyousefz@yahoo.com that I have disagreed with the use of CT in diagnosis of malrotation. On the contrary, CT, like any other crosssectional imaging modality, i.e. US and MRI, is an excellent and fully trustworthy modality to demonstrate the retromesenteric D3. In fact, this was first published in the adult CT literature 12 years ago and was appropriately referenced in my initial and follow-up publications [2-4]. My reservations [7] pointed to the inaccuracies of Dr. Taylor [6] in presenting his data regarding his single alleged false-negative case, which was addressed in detail in my letter to the editor [7], to the editorial board of Pediatric Radiology and to Dr. George Taylor himself in person.

Once again, I want to congratulate you for your efforts and your major contribution, and respectfully request you correct your incorrect representation of my viewpoints and reservations.

\section{References}

1. Menten R, Reding R, Godding V et al (2012) Sonographic assessment of the retroperitoneal position of the third portion of the duodenum: an indicator of normal intestinal rotation. Pediatr Radiol 42:941-945

2. Yousefzadeh DK (2009) The position of the duodenojejunal junction: the wrong horse to bet on in diagnosing or excluding malrotation. Pediatr Radiol 39(Suppl 2):S172-S177

3. Yousefzadeh DK (2010) US as a primary tool in the work-up of malrotation: reply to Anuradha et al. Pediatr Radiol 40:1846-1847

4. Yousefzadeh DK, Kang L, Tessicini L (2010) Assessment of retromesenteric position of the third portion of the duodenum: a US feasibility study in 33 newborns. Pediatr Radiol 40:1476-1484

5. Strouse PJ (2010) Tempered enthusiasm. Pediatr Radiol 40:1469

6. Taylor GA (2011) CT appearance of the duodenum and mesenteric vessels in children with normal and abnormal bowel. Pediatr Radiol 41:1378-1383

7. Yousefzadeh DK (2011) Regarding online publication of CT appearance of the duodenum and mesenteric vessels in children with normal and abnormal bowel rotation. Pediatr Radiol 41:1481-1482 